\title{
The Effect of Achieving Patient-Reported Outcome Measures on Satisfaction
}

\author{
Leif I. Solberg, MD, Stephen E. Asche, MA, John Butler, MD, David Carrell, PhD, \\ Christine K. Norton, MA, Jeffrey G. Jarvik, MD, MPH, Rebecca Smith-Bindman, MD, \\ Juliana O. Tillema, MPA, Robin R. Whitebird, PhD, and Jeanette Y. Ziegenfuss, PhD
}

Objective: To determine how frequently patients with advanced imaging for back or abdominal pain achieve outcomes that are identified by patients as important and whether those achieving those outcomes are more satisfied.

Methods: Cross-sectional analysis of survey responses from patients of an 800-physician multi-specialty group in Minnesota in 2013. A total of 201 patients with abdominal pain and 167 patients with back pain 1 year earlier that was serious enough for a computed tomography or magnetic resonance imaging scan (67\% of those contacted). The main outcomes were the frequency of occurrence of 19 outcomes previously identified by patients as important, plus satisfaction with the results of care.

Results: The majority of patients surveyed had achieved most of the desired outcomes. For abdominal pain, 17 of 19 of the desired outcomes were achieved by $>50 \%$ of patients, while 11 of 19 desired outcomes were achieved by $>50 \%$ of patients with back pain. Seven of the desired outcomes were significantly associated with satisfaction.

Conclusion: Achieving outcomes important to patients is associated with greater patient satisfaction. Such measures are potentially valuable measures of quality. (J Am Board Fam Med 2015;28:785-792.)

Keywords: Outcome Assessment (Health Care), Pain, Patient Participation, Patient Satisfaction, Patient-Centered Care

Patient-reported outcome measures (PROMs) are becoming increasingly important to research, performance reporting, and quality improvement efforts, but this field is still in a relatively early stage

This article was externally peer reviewed.

Submitted 23 February 2015; revised 18 May 2015; accepted 21 May 2015.

From the HealthPartners Institute for Education and Research, Minneapolis MN (LIS, SEA, JOT, RRW, JYZ); the HealthPartners Medical Group, Minneapolis MN (JB); the Group Health Research Institute, Seattle WA (DC); the University of Washington, Seattle (JGJ); and the University of California, San Francisco (RS-B).

Funding: This work was supported through a PatientCentered Outcomes Research Institute (PCORI) Pilot Project Program Award.

Conflict of interest: LIS is a board member of the ICSI regional quality improvement collaborative, is employed by HealthPartners health systems, has a pending PCORI grant, and received grants from Centers for Medicare and Medicaid Services, the National Institutes of Health, and PCORI. JGJ is a board member of the GE-AUR Radiology Research Academy Fellowship Advisory Board, attended the GEAUR Radiology Research Academy Fellowship Retreat, received a patent for PhysioSonics (an ultrasound-based diagnostic company), and receives royalties for PhysioSonics. RS-B received a grant from PCORI. of development. ${ }^{1}$ While the term PROM can refer to any outcome that is reported by patients, what is important about such measures is that they are presumed to address topics that are more important to patients than the clinical measurements that physicians have traditionally relied on (eg, control of blood pressure, A1C level). While the increased priority for PROMs may be largely because of the emphasis given to them by the new funding institute Patient-Centered Outcomes Research Institute, they are rapidly gaining the attention of many funders, policymakers, and health system leaders. $^{2-4}$ Many seem to agree with Black $^{5}$ that

\footnotetext{
Disclaimer: All statements in this report, including its findings and conclusions, are solely those of the authors and do not necessarily represent the views of the Patient-Centered Outcomes Research Institute (PCORI), its board of governors, or methodology committee.

Corresponding author: Leif I. Solberg, MD, HealthPartners Institute for Education and Research, PO Box 1524, MS\#22301A, Minneapolis MN 55440-1524 (E-mail: Leif. I.Solberg@HealthPartners.com).
} 
PROMs could help to transform health care, both by helping patients and clinicians make better decisions and by driving service improvements by enabling comparisons of performance on outcomes that matter to patients.

As with any new field, there are conflicting perspectives on what is meant by "PROMs" and what they should measure. Most researchers emphasize highly quantitative measures of specific symptoms and functions, such as those included in the domains of emotional distress, alcohol, pain, and sexual function by the Patient-Reported Outcomes Measurement Information System (PROMIS), created by the National Institutes of Health in 2004. ${ }^{6-8}$ Although the PROMIS measures are selected for high reliability, validity, comparability, flexibility, and inclusiveness, they do not seem to have been developed to address outcomes that are important to patients. When we asked 8 patients with previous episodes of abdominal or back pain which outcomes were important to them, they instead named broad life functions and care processes such as returning to work, avoiding burden on family, and avoiding hospitalizations and surgery. ${ }^{9}$ We tested those outcomes with another group of 40 patients with these problems and 11 close family members, creating a suite of 19 outcomes that they rated as important to them $(>3.5$ on a scale of 1 to 5). Interestingly, while the clinical problems associated with back and abdominal pain are heterogeneous and different from each other, the importance ratings for these outcomes were very similar between the 2 conditions.

If these outcomes are truly important to patients, measuring the frequency of their occurrence should become standard in clinical care, research, and performance measurement or quality improvement. Therefore, the objective of this pilot study was to determine how frequently patients who have undergone advanced imaging for abdominal or back pain believe that they have achieved each of the outcomes identified by patients in the abovementioned survey (not just any "patient-reported outcomes") and whether those who do so are more satisfied with the results of their care than those who do not. Since patients with these quite different clinical problems gave similar importance ratings to these outcomes, comparing them became a secondary objective.

\section{Methods \\ Setting}

We conducted this study among patients receiving care from an 800-physician multispecialty medical group in the Minneapolis-St. Paul metropolitan area that is affiliated with a health insurance plan. To facilitate access to health plan claims data for these patients for a later phase of the study, we limited patient recruitment to the $60 \%$ of medical group patients having insurance from that health plan. This population (about 500,000 people) includes patients in prepaid Medicare and Medicaid programs and is demographically similar to that of the Twin Cities metropolitan area.

\section{Patients}

We identified the patient sample from the group's electronic medical record as those adults who had undergone advanced imaging-either magnetic resonance imaging or computed tomography—ordered by a primary care physician for abdominal or back pain approximately 1 year before our survey. We chose this time period to allow sufficient time for the desired outcomes to occur. These criteria identified 655 patients, 389 with abdominal pain and 266 with back pain, who had such scans in the preceding 11 to 20 months.

\section{Survey}

In a previous survey that asked similar patients to identify and rate the importance of outcomes from the care received for their back or abdominal pain, they identified 19 outcomes that were important to them. ${ }^{9}$ Patient ratings of the importance of these outcomes on a scale from 1 (not at all important) to 5 (extremely important) averaged 4.1 (standard deviation $[\mathrm{SD}], 1.1)$ for abdominal pain and 4.5 (SD, 0.8 ) for back pain, and none were below 3.3. Table 1 lists these outcomes in order of their importance scores. In addition, patients wanted to be satisfied with the results of their care (4.7) and with the way the care was delivered (4.5).

In the absence of any existing survey that asked about these outcomes, we created questions that were designed to learn whether each outcome occurred and, if it did, when it occurred. We first tested these questions with members of our patient advisory board-people who experienced these same problems and agreed to serve as study advisers (half with each of the 2 problems). Then we revised 
Table 1. Outcomes Considered Important by Patients with Back or Abdominal Pain, Ranked by Their Importance Ratings*

\begin{tabular}{lc}
\hline Outcome & Importance \\
\hline 1. To find the cause of the pain & 4.9 \\
2. To trust that the treatment plan is appropriate & 4.7 \\
3. To return to normal life functions & 4.7 \\
4. To understand what may happen to you & 4.6 \\
because of the problem & \\
5. To prevent this problem from occurring again & 4.6 \\
6. To prevent long-term loss of function & 4.6 \\
7. To return to work and productivity as soon as & 4.5 \\
possible & \\
8. To experience no complications or side effects & 4.3 \\
9. To be assured that no unexpected, unrelated & 4.2 \\
problems develop & \\
10. To get rapid and complete relief from pain & 4.2 \\
and other symptoms & \\
11. To avoid being hospitalized & 4.1 \\
12. To avoid surgery & 4.1 \\
13. To avoid placing a burden or stress on family & 4.1 \\
members & \\
14. To minimize or avoid the need for further & 3.9 \\
tests and medical visits & 3.7 \\
15. To minimize radiation exposure in the & 3.9 \\
course of my care & \\
16. To avoid personal costs for care \\
17. To minimize or avoid use of medication \\
18. To return to leisure/sports activities as soon \\
as possible \\
19. To minimize discomfort from the tests used \\
to assess the pain \\
\hline
\end{tabular}

*Ratings were made on a scale from 1 to 5 , where 1 is "not at all important" and 5 is "extremely important."

the questions for telephone administration by trained interviewers. To the outcome questions we added standard demographic questions and a standardized study introduction script. We first mailed a letter to all those identified to notify them of the survey and to provide them a chance to opt out of being called. Individuals who completed the survey were given a gift card as a thank you for participation. All aspects of the process and content of the survey were reviewed, approved, and monitored by the HealthPartners Institutional Review Board.

\section{Analysis}

Patient attributes and their achievement of desired outcomes were summarized with descriptive statistics (mean, SD, proportion). Differences among patients with abdomen and back pain regarding patient attributes and achievement of outcomes were tested with independent samples $t$ tests, contingency tables, and Pearson or Mantel-Haenszel $\chi^{2}$ or Fisher exact tests. The associations between achievement of each desired outcome and patient satisfaction were tested with Pearson $\chi^{2}$ or Fisher exact test. To simplify presentation of results while preserving at least a modest degree of balance, we recoded patient satisfaction measures as "very satisfied" versus all lower satisfaction categories, and we similarly recoded patient dissatisfaction measures as "somewhat or very dissatisfied" versus "neutral" or "satisfied."

\section{Results}

\section{Survey Process}

Of the 655 patients who fit the inclusion criteria, 16 called us to opt out of being called (12 with abdominal pain and 4 with back pain) and 26 did not fit our criteria (22 with abdominal pain and 4 with back pain), leaving 624 potential respondents. Of these, we were able to contact 552 (88.5\%), but 137 (92 with abdominal pain and 45 with back pain) refused to be interviewed and 5 were contacted but did not complete the interview, leaving $167 \mathrm{pa}$ tients with back pain and 201 patients with abdominal pain, for a response rate of $59 \%$ of those who were potentially eligible and $67 \%$ of those who were contacted. Comparison of responders, refusers, and nonresponders showed that there were no significant differences by age, sex, race, ethnicity, or imaging type.

\section{Subjects}

Table 2 provides data on the characteristics of respondents, sorted by pain type. These patients overall were mostly white (87\%) and well-educated (39\% with at least a college degree).There were no significant differences between the 2 groups on demographic variables except that patients with back pain were somewhat more likely than those with abdominal pain to be male and retired or disabled.

\section{Outcomes and Satisfaction}

Table 3 summarizes the frequency with which each outcome occurred. All but 2 of the desired outcomes (returning to work soon and getting rapid and complete pain relief) were achieved by the majority of patients with abdominal pain. For patients with back pain, 8 outcomes were expe- 
Table 2. Characteristics of Survey Completers

\begin{tabular}{|c|c|c|c|}
\hline & $\begin{array}{l}\text { Respondents with Abdominal Pain } \\
\qquad(\mathrm{n}=201)\end{array}$ & $\begin{array}{l}\text { Respondents with Back Pain } \\
\qquad(\mathrm{n}=167)\end{array}$ & $P$ Value \\
\hline Female sex & $132(66)$ & $98(59)$ & .17 \\
\hline Age (years), mean (SD) & $54.6(17)$ & $55.7(16)$ & .54 \\
\hline \multicolumn{4}{|l|}{ Race } \\
\hline White & $175(88)$ & $140(86)$ & .56 \\
\hline Hispanic or Latino & $10(5)$ & $6(4)$ & .53 \\
\hline \multicolumn{4}{|l|}{ Relationship status } \\
\hline Married, living with partner & $130(65)$ & $115(69)$ & .14 \\
\hline $\begin{array}{l}\text { Separated, divorced, } \\
\text { widowed }\end{array}$ & $39(20)$ & $38(23)$ & \\
\hline Never married & $30(15)$ & $14(8)$ & \\
\hline \multicolumn{4}{|l|}{ Education } \\
\hline High school or less & $52(26)$ & $45(27)$ & .70 \\
\hline Some college or tech school & $70(35)$ & $55(33)$ & \\
\hline College graduate & $52(26)$ & $40(24)$ & \\
\hline Postgraduate degree & $24(12)$ & $27(16)$ & \\
\hline \multicolumn{4}{|l|}{ Work status } \\
\hline Employed, self-employed & $121(60)$ & $88(53)$ & .12 \\
\hline Out of/unable to work & $11(6)$ & $14(8)$ & \\
\hline Homemaker & $10(5)$ & $6(4)$ & \\
\hline Student & $2(1)$ & $1(1)$ & \\
\hline Retired & $56(28)$ & $57(34)$ & \\
\hline
\end{tabular}

Data are n (\%) unless otherwise indicated. Differences by study group (abdomen or back) were tested using the Pearson $\chi^{2}$ test, Fisher exact test, or independent samples $t$ test. SD, standard deviation.

rienced by $<50 \%$ of patients, with the same 2 outcomes lowest. Patients with abdominal pain were more likely than patients with back pain to achieve 11 of 21 outcomes, whereas patients with back pain were more likely than those with abdominal pain to achieve only 2 of 21 outcomes. Most patients were very satisfied with the results of their care: $84 \%$ of patients with abdominal pain and $74 \%$ of those with back pain (data not shown).

Additional questions provided further detail about some of the outcomes. While $63 \%$ and $78 \%$ learned the cause of their pain, $60 \%$ and $70 \%$ reported learning the cause of their pain from the scan, and the rest either knew it beforehand or learned later. Even 1 year later, $13 \%$ of patients with abdominal pain and $30 \%$ with back pain reported having obtained no relief. Finally, 4\% of patients with abdominal pain reported having complications from their treatments, and $5 \%$ reported experiencing serious unexpected problems unrelated to the cause of their pain (only 1 of 10 had both complications and unexpected unrelated problems).
Table 4 reports the relationship between achieving desired outcomes and satisfaction with the results of care. Patients were significantly more likely to be very satisfied if they experienced any of 8 of the 19 outcomes. Five of those 8 outcomes satisfied both patients with back pain and those with abdominal pain (learned cause and what may happen, obtained complete pain relief, trusted treatment, and avoided long-term function loss). Two other outcomes were associated with high satisfaction for only patients with back pain (minimized medical tests and visits, and returned to normal life functions by 1 month) and 1 (avoiding family burden) for only patients with abdominal pain.

We also tested the relationship between achieving desired outcomes and dissatisfaction (responses of very or somewhat dissatisfied). Five outcomes were related to dissatisfaction but not related to satisfaction. Patients with abdominal pain who did not return to normal life function soon were more dissatisfied than those that $\operatorname{did}(19 \%$ vs $4 \%$ dissatisfied; $P=.02)$, as were those who had personal costs $(17 \%$ vs $7 \%$ dissatisfied; $P=.04)$. Patients with back pain who had complications, who had 
Table 3. Frequency of Achieving Outcomes Important to Patients (Ranked by Importance Rating)

\begin{tabular}{|c|c|c|c|}
\hline Outcome & $\begin{array}{l}\text { Patients with Abdominal Pain } \\
\qquad(\mathrm{n}=201)\end{array}$ & $\begin{array}{l}\text { Patients with Back Pain } \\
\qquad(\mathrm{n}=167)\end{array}$ & $P$ Value \\
\hline Found the cause of the pain & $126 / 201(63)$ & $131 / 167(78)$ & .001 \\
\hline Trusted that the treatment plan was appropriate & $158 / 183(86)$ & $127 / 153(83)$ & .40 \\
\hline Returned to normal life function by 1 month & $73 / 115(63)^{*}$ & $38 / 145(26)^{* \dagger}$ & $<.001$ \\
\hline $\begin{array}{l}\text { Understood (somewhat or very much) what may } \\
\text { happen to them because of the problem }\end{array}$ & $142 / 201(71)$ & $132 / 167(79)$ & .07 \\
\hline Avoided pain recurrence & $101 / 115(88)^{\ddagger}$ & $33 / 46(72)^{\ddagger}$ & .01 \\
\hline Avoided long-term loss of function & $31 / 42(74)^{\S}$ & $51 / 106(48)^{+\$}$ & .005 \\
\hline Returned to work and productivity soon & $10 / 46(22)^{\dagger \uparrow}$ & $10 / 53(19)^{\dagger+\mathbb{I}}$ & .72 \\
\hline $\begin{array}{l}\text { Experienced no complications or side effects } \\
\text { related to the cause or treatment of pain }\end{array}$ & $176 / 192(92)$ & $88 / 163(54)$ & $<.001$ \\
\hline $\begin{array}{l}\text { Avoided unexpected problems not related to } \\
\text { pain }\end{array}$ & $172 / 192(87)$ & $154 / 162(95)$ & .01 \\
\hline Got rapid (within 1 week) and complete relief & $50 / 196(26)^{\dagger}$ & $8 / 165(5)^{\dagger}$ & $<.001$ \\
\hline Avoid hospitalization & $180 / 201(90)$ & $155 / 167(93)$ & .28 \\
\hline Avoided surgery & $167 / 200(84)$ & $145 / 166(87)$ & .30 \\
\hline Avoided burden on family & $135 / 201(67)$ & $81 / 167(49)^{\dagger}$ & .003 \\
\hline Avoided further tests, visits, treatments & $121 / 196(62)$ & $76 / 162(47)^{\dagger}$ & .005 \\
\hline Avoided additional radiation exposure & $180 / 195(92)$ & $156 / 164(95)$ & .28 \\
\hline Avoided personal costs of care & $118 / 201(59)$ & $85 / 166(51)$ & .15 \\
\hline Minimized use of medications & $122 / 199(61)$ & $66 / 167(40)^{\dagger}$ & $<.001$ \\
\hline $\begin{array}{l}\text { Returned to leisure/sports activities within a few } \\
\text { weeks }\end{array}$ & $150 / 197(76)$ & $49 / 166(30)^{\dagger}$ & $<.001$ \\
\hline Minimized uncomfortable tests or treatment & $167 / 201(83)$ & $102 / 167(61)$ & $<.001$ \\
\hline
\end{tabular}

Data are $\mathrm{n} / \mathrm{N}(\%)$.

*Limited to patients whose pain interfered with day-to-day functioning at the time of the scan.

${ }^{\dagger}<50 \%$ Of patients experienced the outcome.

${ }^{\ddagger}$ Limited to patients whose pain went away completely after the pain episode.

${ }^{\S}$ Limited to patients whose pain interfered with day-to-day functioning at the time of the scan and pain was still affecting functioning 1 month after the scan.

"ILimited to patients who were working outside the home before the pain episode and who missed work or were not fully productive because of pain.

uncomfortable testing, and who did not return to sports and leisure were twice as likely to report being dissatisfied with their results $(P=.008, P=$ .008 , and $P=.03$ respectively).

For both patients with abdominal pain and patients with back pain, satisfaction with results of care were not statistically significantly associated with sex, age group, race, ethnicity, relationship status, or employment status. Patients with abdominal pain were more likely to be satisfied with their results if they had either a high school education or less (67\% satisfied) or a postgraduate degree $(73 \%)$ than if they had some college $(50 \%)$ or were college graduates $(54 \%)$.

\section{Discussion}

Most of these patients achieved most of the desired outcomes, but patients with back pain were less likely to do so than those with abdominal pain. A sizeable minority of people did not achieve desired outcomes, however, and that often was associated with lower satisfaction or higher dissatisfaction. The fact that at least 12 of the 19 outcomes were associated with satisfaction provides evidence that these PROMs are truly important to patients, especially finding out the cause of the pain, trusting the treatment plan, returning to normal life function, understanding what may happen, and avoiding long-term loss of function (see Table 4).

Some of the PROMs were not associated with patient satisfaction. When we presented these findings to our patient and clinician advisory panels, they thought it was not surprising that some outcomes might not be associated with satisfaction, even though each of the outcomes was important in isolation. One patient pointed out that most of the 
Table 4. Relationship between Achieving Outcomes and Satisfaction with Results of Care (Ranked by Importance of Outcome to Patients)

\begin{tabular}{|c|c|c|c|c|}
\hline \multirow[b]{2}{*}{ Outcome } & \multicolumn{2}{|c|}{ Patients with Abdominal Pain } & \multicolumn{2}{|c|}{ Patients with Back Pain } \\
\hline & Very Satisfied (\%) & $P$ Value & Very Satisfied (\%) & $P$ Value \\
\hline \multicolumn{5}{|c|}{ Found out the cause of the pain } \\
\hline Yes & 75 & \multirow[t]{2}{*}{$<.01$} & 47 & \multirow[t]{2}{*}{.02} \\
\hline No & 44 & & 25 & \\
\hline \multicolumn{5}{|c|}{ Trusted that the treatment plan was appropriate } \\
\hline Yes & 72 & \multirow[t]{2}{*}{$<.01$} & 53 & \multirow[t]{2}{*}{$<.01$} \\
\hline No & 24 & & 8 & \\
\hline \multicolumn{5}{|c|}{ Returned to normal life function by 1 month } \\
\hline Yes & 73 & \multirow[t]{2}{*}{.05} & 66 & \multirow[t]{2}{*}{$<.01$} \\
\hline No & 55 & & 36 & \\
\hline \multicolumn{5}{|c|}{ Understood what may happen } \\
\hline Some or very much & 73 & \multirow[t]{2}{*}{$<.01$} & 50 & \multirow[t]{2}{*}{$<.01$} \\
\hline Not at all & 39 & & 11 & \\
\hline \multicolumn{5}{|l|}{ Avoided recurrence } \\
\hline Yes & 77 & \multirow[t]{2}{*}{.29} & 65 & \multirow[t]{2}{*}{.29} \\
\hline No & 64 & & 85 & \\
\hline \multicolumn{5}{|c|}{ Avoided long-term loss of function } \\
\hline Yes & 64 & \multirow[t]{2}{*}{.04} & 61 & \multirow[t]{2}{*}{$<.01$} \\
\hline No & 27 & & 15 & \\
\hline \multicolumn{5}{|c|}{ Returned to work and productivity soon } \\
\hline Yes & 70 & .72 & 40 & .91 \\
\hline No & 64 & & 42 & \\
\hline Avoided complications/ & & & & \\
\hline Yes & 64 & .26 & 49 & .10 \\
\hline No & 50 & & 36 & \\
\hline Avoided unexpected pr & & & & \\
\hline Yes & 63 & .74 & 44 & .14 \\
\hline No & 60 & & 12 & \\
\hline Got rapid and complet & & & & \\
\hline Yes & 78 & $<.01$ & 88 & .01 \\
\hline No & 57 & & 40 & \\
\hline Avoided hospitalization & & & & \\
\hline Yes & 63 & .73 & 40 & .07 \\
\hline No & 67 & & 67 & \\
\hline Avoided surgery & & & & \\
\hline Yes & 60 & .10 & 40 & .13 \\
\hline No & 76 & & 57 & \\
\hline Avoided burden on fam & & & & \\
\hline Yes & 70 & $<.01$ & 44 & .52 \\
\hline No & 50 & & 40 & \\
\hline Minimized medical test & & & & \\
\hline Yes & 69 & .07 & 53 & .02 \\
\hline No & 56 & & 35 & \\
\hline Avoided additional radi & & & & \\
\hline Yes & 63 & .80 & 43 & .32 \\
\hline No & 67 & & 25 & \\
\hline Avoided personal costs & & & & \\
\hline Yes & 64 & .67 & 42 & .97 \\
\hline No & 62 & & 42 & \\
\hline
\end{tabular}




\begin{tabular}{|c|c|c|c|c|}
\hline \multirow[b]{2}{*}{ Outcome } & \multicolumn{2}{|c|}{ Patients with Abdominal Pain } & \multicolumn{2}{|c|}{ Patients with Back Pain } \\
\hline & $\begin{array}{c}\text { Very Satisfied } \\
(\%)\end{array}$ & $P$ Value & $\begin{array}{c}\text { Very Satisfied } \\
(\%)\end{array}$ & $P$ Value \\
\hline \multicolumn{5}{|c|}{ Minimized use of medications } \\
\hline Yes & 58 & .06 & 39 & .59 \\
\hline No & 71 & & 44 & \\
\hline \multicolumn{5}{|c|}{ Returned to leisure/sports soon } \\
\hline Yes & 67 & .09 & 47 & .42 \\
\hline No & 53 & & 40 & \\
\hline \multicolumn{5}{|c|}{ Avoided uncomfortable tests } \\
\hline Yes & 63 & .85 & 41 & .80 \\
\hline No & 62 & & 43 & \\
\hline
\end{tabular}

outcomes correlated with satisfaction were positively stated, whereas most of those without such correlations were stated in terms of avoiding some aspect of care. They noted that if some otherwise undesirable outcomes (surgery, hospitalization, painful tests, medications, radiation, personal costs) seemed to have been important in achieving other outcomes in individual cases, then they might seem worth it and not dissatisfying. They also pointed out that feeling respected and cared about could overcome even very undesirable outcomes. Further, the rates of achieving most desired outcomes were high, leaving few respondents with an opportunity to be dissatisfied. Therefore, we suggest that all 19 outcomes should remain in the suite of PROMs and undergo further study in different populations and situations.

The 2 pain conditions studied here (back and abdominal pain) are each internally heterogeneous as well as quite different from each other in many ways: cause, duration, treatment, and impact on life functions. Nevertheless, patients with either of these 2 conditions have previously rated these outcomes to be similarly important and they now report mostly similar frequencies of experiencing those important outcomes. This suggests that such general outcomes may be able to be used as patientcentered measures for a variety of conditions - that it may not be necessary to have completely different outcome measures for each medical condition as has been proposed. That could greatly simplify the otherwise imposing and logistically difficult task of measuring and reporting PROMs that are condition-specific. Of course, it may also be helpful and even necessary to include some of the specific symptom and bodily function measures in the
PROMIS set for research and performance comparisons. But in a time when patient experience and patient-centeredness have the high priority they are currently developing, it seems important also to include quality of life measures like these that seem to be meaningful to patients and their families.

We identified only a few articles in the scientific literature that have considered the relationship between outcomes important to patients and satisfaction. The most similar effort is that of the Beacon group at the Mayo Clinic, which confirmed from patient discussion groups that patients are interested in a much broader and more personal set of outcomes than simply those limited to symptoms or specific functions. ${ }^{10}$ Sun et $\mathrm{al}^{11}$ showed that disability improvements after epidural injections for spinal stenosis were related to patient satisfaction. Most randomized controlled trials measure technical surrogates as outcomes, such as degree of control of some physiologic variable, although major health events (death, acute events) and side effects also are often assessed. It should not be difficult or expensive to add to those trials outcomes like the ones described here, nor should it be hard to include them as performance measures and quality improvement targets. Better understanding of what outcomes are desirable to patients and how these correlate with overall satisfaction may guide the creation of more useful and effective patient information and shared decision-making materials that provide realistic expectations for care for patients. Santana et $\mathrm{al}^{12}$ published a framework for how such patient-reported outcomes may be incorporated into clinical care.

As an early venture in this new focus on patientcenteredness and patient-reported outcomes, there 
are many limitations to this study. The conditions studied are indeed heterogeneous, and our list of potentially important outcomes is far from exhaustive. Nor did we ask patients to compare these outcomes with other more commonly assessed outcomes. The survey questions used have not been evaluated for their psychometric properties, and we did not verify the validity of the answers.

However, based on these data we suggest that there is another dimension for PROMs, one that is not only patient-reported, but patient-centered, perhaps called "PC-PROMs" since it is often associated with patient satisfaction with their care and results. Neuburger et $\mathrm{al}^{13}$ demonstrated that the choice of patient-reported outcomes measures can make a very large difference in the performance ratings of individual surgeons. In conclusion, we recommend choosing outcome measures that are not only patient-reported but also important to patients and associated with greater satisfaction.

The authors are very grateful for the excellent work done by the staff of the HealthPartners Survey Center in conducting the patient survey on which this study is based, and to Cally Vinz, $\mathrm{RN}$, vice president at ICSI, who has been an active participant in our meetings and helped to identify and recruit physicians for interviews. The authors also have been greatly helped by review and feedback from the members of the patient advisory board and physician advisory board for this study. Their comments reassured us that the interpretations in this article are important and reasonable. This includes Jenny Zakoski, David Freedland, and Gail Soens from the patient/family advisory board, who have been provided with a modest honorarium for their time. In addition, John Wilkinson, MD; Ian Kenning, MD; and Deepti Pandita, MD from the physician advisory board reviewed our plans and findings and provided us with practicing physician perspectives that have helped us to remain focused on that part of our audience, even though we were unable to provide them with any recompense.

\section{References}

1. Solberg LI. Patient outcomes measures-the next promising answer? Fam Pract 2014;31:245-6.

2. Butt Z, Reeve B. Enhancing the patient's voice: standards in the design and selection of patient-reported outcomes measures (PROMs) for use in patient-centered outcomes research. Washington, DC: PatientCentered Outcomes Research Institute; 2012.

3. Howie L, Hirsch B, Locklear T, Abernethy AP. Assessing the value of patient-generated data to comparative effectiveness research. Health Aff (Millwood) 2014;33:1220-8.

4. Bitton A, Onega T, Tosteson AN, Haas JS. Toward a better understanding of patient-reported outcomes in clinical practice. Am J Manag Care 2014;20: 281-3.

5. Black N. Patient reported outcome measures could help transform healthcare. BMJ 2013;346:f167.

6. Tucker CA, Cieza A, Riley AW, et al. Concept analysis of the Patient Reported Outcomes Measurement Information System (PROMIS) and the International Classification of Functioning, Disability and Health (ICF). Qual Life Res 2014;23:1677-86.

7. Gershon RC, Rothrock N, Hanrahan R, Bass M, Cella D. The use of PROMIS and assessment center to deliver patient-reported outcome measures in clinical research. J Appl Meas 2010;11:304-14.

8. Cella D, Riley W, Stone A, et al. The PatientReported Outcomes Measurement Information System (PROMIS) developed and tested its first wave of adult self-reported health outcome item banks: 2005-8. J Clin Epidemiol 2010;63:1179-94.

9. Solberg LI, Asche SE, Butler JC, et al. It is time to ask patients what outcomes are important to them. Am J Account Care (in press).

10. Ridgeway JL, Beebe TJ, Chute CG, et al. A brief Patient-Reported Outcomes Quality of Life (PROQOL) instrument to improve patient care. PLoS Med 2013;10:e1001548.

11. Sun P, Pashova H, Heagerty PJ, et al. Short-term improvements in disability mediate patient satisfaction after epidural corticosteroid injections for symptomatic lumbar spinal stenosis. Spine (Phila Pa 1976) 2015;40:1363-70.

12. Santana MJ, Feeny D. Framework to assess the effects of using patient-reported outcome measures in chronic care management. Qual Life Res 2014;23: 1505-13.

13. Neuburger J, Hutchings A, van der Meulen J, Black N. Using patient-reported outcomes (PROs) to compare the providers of surgery: does the choice of measure matter? Med Care 2013;51:517-23. 